\title{
A novel model of dermatomyositis induced by membrane antigen and calciphylaxis in rats
}

\author{
XIN ZHAO*, LINGYU LI* ${ }^{*}$, SHASHA GE, JINYU LIU, SHUANG LI, HONGYA WANG and DAYONG CAI \\ Institute of Medicinal Plant Development, Chinese Academy of Medical Sciences, \\ Peking Union Medical College, Beijing 100193, P.R. China
}

Received November 12, 2021; Accepted January 18, 2022

DOI: $10.3892 /$ br.2022.1514

\begin{abstract}
Dermatomyositis (DM) is a severe autoimmune disease of the connective tissue characterized by inflammatory and degenerative changes in the skin and muscle. However, the lack of experimental models of DM represents a challenge for the development of effective drugs. The aim of the present study was to establish a pharmacodynamic rat model of DM that would recapitulate the clinical manifestation seen in patients. The DM model was established using membrane antigen-induced autoimmune injury, followed by toxin-induced subcutaneous calciphylaxis. The rats were divided into five groups and were subcutaneously injected with membrane antigen. Of these, four antigen-immunized groups then received dihydrotestosterone (DHT), iron-dextrin (Fe-Dex), polymyxin (PMX) either individually or in combination to induce cutaneous calciphylaxis. The clinical manifestation score, ratio of infiltrated lymphocytes, ratio of arteriole calcified nodules in skeletal muscles, serum antibody levels [anti-histidyl tRNA synthetase (Jo-1) and anti-melanoma differentiation-associated protein 5 (MDA5)] and serum cytokine levels [tumor necrosis factor- $\alpha(\mathrm{TNF}-\alpha)$ and interferon- $\gamma$ $(\mathrm{IFN}-\gamma)]$ were then detected. The results demonstrated that all five autoimmune groups displayed local cutaneous swelling and weakness, increased serum antibody and cytokine levels, and T lymphocyte infiltration in perimysial and perivascular sites. Moreover, pathological changes indicative of calciphylaxis were observed in the PMX and DHT + Fe-Dex + PMX. Among all groups, the rats in the PMX and DHT + Fe-Dex + PMX displayed characteristics most closely resembling those of DM pathogenesis in patients. In conclusion, membrane antigen
\end{abstract}

Correspondence to: Dr Dayong Cai, Institute of Medicinal Plant Development, Chinese Academy of Medical Sciences, Peking Union Medical College, 151 Malianwa North Road, Haidian, Beijing 100193, P.R. China

E-mail: dycai@implad.ac.cn

${ }^{*}$ Contributed equally

Key words: dermatomyositis, autoimmune, calciphylaxis, experimental model immunization combined with toxin-induced calciphylaxis can be used as a DM model in rats. This model may be used for the development of effective drugs for DM treatment.

\section{Introduction}

Dermatomyositis (DM) is a systemic autoimmune disorder with high mortality (50-70\% mortality rate) (1). It is characterized by progressive proximal skeletal muscle weakness, Gottron papules, heliotrope rash, and histopathological changes in cutaneous rashes (including calcinosis and ulceration) (2-4). Furthermore, this disease is always associated with extramuscular manifestations such as interstitial lung disease and malignancies, which are a major cause of death (5-7). The development of suitable animal models of DM pathogenesis is of relevance for improving our understanding of the pathophysiology and improving therapeutic options.

The mechanisms of DM include autoimmune responses (8) and calciphylaxis (9). Humoral and cell-mediated responses are involved in the pathogenesis of DM. DM is the result of complement 5b-9 (C5b-9) deposition in endomysial vasculature, leading to inflammation of the microvasculature, which in turn results in muscle atrophy (10). However, the autoantibodies targeting endothelial cell antigens have not been identified (11). In patients with DM, the immune cells in perimysial and perivascular infiltrates comprise mainly $\mathrm{CD}^{+}$ $\mathrm{T}$ cells (12). The skin lesions also show perivascular inflammation with $\mathrm{CD}^{+} \mathrm{T}$ cells in the dermis (13). Cell-mediated immune responses also play a leading role in DM (14). Moreover, slight calciphylaxis in DM was demonstrated as the precipitating factor for the generation of calcified nodules in cutaneous arterioles (15).

In the present study, a novel DM model in rats was established using allogeneic plasma membrane protein-induced autoimmune injury, followed by toxin-induced calciphylaxis (16). The membrane proteins were extracted from the skeletal muscle and adjacent subcutaneous connective tissue of normal rats, then emulsified with complete Freund's adjuvant (CFA) to prepare membrane antigen. The rats received membrane antigen sensitization and challenge to induce autoimmune injury. Cutaneous calciphylaxis was then induced with dihydrotestosterone (DHT), iron-dextrin (Fe-Dex), polymyxin (PMX), either alone or in combination, as previous study described (9). Clinical manifestations, serum levels of 
specific antibodies and cytokines, and pathological changes were detected to evaluate the establishment of the DM model.

\section{Materials and methods}

Animals and materials. A total of 60 female SD rats (7 weeks old, weighting $160 \pm 10 \mathrm{~g}$ ) were obtained from Animal Centre of the Chinese Academy of Medical Sciences. Animals were maintained in a temperature $\left(25.0 \pm 0.2^{\circ} \mathrm{C}\right)$ and humidity $(45 \% \pm 5 \%)$ controlled specific pathogen free laboratory, under a 12-light/dark cycle, fed with standard rodent pellets and allowed free access to filtered water. The animals were acclimatized for three days. All experimental procedures were approved by the Ethics Committee of the Institute of Medicinal Plant Development, Chinese Academy of Medical Sciences and Peking Union Medical College (approval no. SLXD-20170705016).

DHT (cat. no. C10033864), Fe-Dex (cat. no. 50807A-1), PMX (cat. no. 1405-20-5) and CFA (cat. no. 1001646446) were obtained from MilliporeSigma. A Tissue Membrane Protein Extraction Kit (cat. no. KGP3100-2) was obtained from Nanjing KeyGen Biotech Co., Ltd. The ELISA kits used for the detection of rat anti-histidyl tRNA synthetase (Jo-1) antibody (cat. no. QS49908), anti-melanoma differentiation-associated protein 5 (MDA5) antibody (cat. no. QS49938), tumor necrosis factor- $\alpha$ (TNF- $\alpha$; cat. no. QS41721), and interferon- $\gamma$ (IFN- $\gamma$; cat. no. QS44104) were purchased from Beijing Qisong Biotechnology Co., Ltd. Among all the rats, 12 rats were used as donors for allogeneic plasma membrane antigen preparation.

Allogeneic plasma membrane antigen preparation. The plasma membrane antigen preparation was modified from a method described previously (17) under aseptic conditions. Briefly, membrane proteins were obtained from 12 wild-type female SD rats. The rats were euthanized under anesthesia by intraperitoneal injection of sodium pentobarbital $(50 \mathrm{mg} / \mathrm{kg})$. After the blood was taken from abdominal aorta, normal saline $(20 \mathrm{ml} / \mathrm{rat})$ was perfused to eliminate remaining blood. Death was confirmed when the spontaneous breathing ceased. The trapezius, gastrocnemius, and their nearby subcutaneous connective tissue were then collected. The tissue samples were rinsed with pre-cooled phosphate buffer saline, and adipose tissue was removed. The samples were then cut to small pieces $(0.2 \times 0.2 \times 0.2 \mathrm{~mm})$ and homogenized in lysis buffer by sonication(power $500 \mathrm{~W}$, pulses of $15 \mathrm{sec}$ on $10 \mathrm{sec}$ off, with $30-40$ cycles). The membrane protein was extracted from the samples using a membrane protein extraction kit, according to the manufacturer's instructions. The extracted samples were quantified using a BCA assay and adjusted to the concentration of $10.0 \mathrm{mg} / \mathrm{ml}$. Lastly, the membrane protein $(10 \mathrm{mg} / \mathrm{ml})$ was emulsified with an equal volume of CFA.

Experimental design. The rats were randomly divided into 6 groups ( $\mathrm{n}=8 /$ group), including a control group and five immunized groups. Rats in all five immunized groups received $10 \mathrm{mg} / \mathrm{kg}$ membrane antigen subcutaneously once weekly from $d_{01}$ to $d_{28}$ for sensitization immunization. A total of 14 days after the last sensitization immunization, these rats received membrane antigen challenge immunization with subcutaneous administration once weekly from $\mathrm{d}_{42}$ to $\mathrm{d}_{63}$. Rats in the control group were

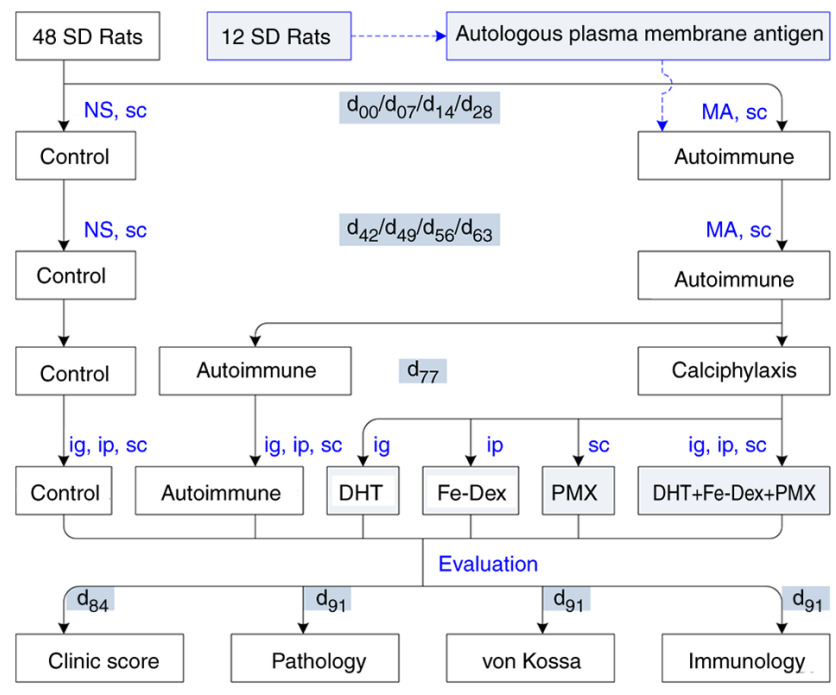

Figure 1. Experimental procedure. $48 \mathrm{SD}$ rats were randomly divided into autoimmune and control groups. The control group received NS sc. Fourteen days weekly MA sensitization for 4 consecutive weeks from $\mathrm{d}_{00}$, the rats in the five autoimmune groups were challenged weekly with plasma MA sc for 4 consecutive weeks from $\mathrm{d}_{42}$. The rats in the calciphylaxis group were divided into DHT, Fe-Dex, PMX and DHT + Fe-Dex + PMX groups at $\mathrm{d}_{77}$, the DHT group was administered DHT (10 mg/kg ig). The Fe-Dex group was administered Fe-Dex $(10 \mathrm{mg} / \mathrm{kg}$ ip). The PMX group was given PMX (20 mg/kg sc). The DHT + Fe-Dex + PMX group received all three toxins (DHT10 mg/kg $+10 \mathrm{mg} / \mathrm{kg} \mathrm{Fe}-$ Dex $+20 \mathrm{mg} / \mathrm{kg}$ PMX). Clinical manifestations in each experimental animal were scored on $\mathrm{d}_{84}$ according to the assessment of dermatomyositis symptoms. Pathological features were examined using hematoxylin and eosin staining, cutaneous calciphylaxis was evaluated using von Kossa staining, and autoimmune injuries were evaluated based on the serum levels of antibodies and cytokines at $\mathrm{d}_{91}$. NS, normal saline; MA, membrane antigen; sc, subcutaneously; ig, intragastrically; ip, intraperitoneally; DHT, dihydrotestosterone; Fe-Dex, iron-dextrin; PMX, polymyxin.

subcutaneously administered normal saline $(1.00 \mathrm{ml} / \mathrm{kg})$. At $\mathrm{d}_{77}$, four groups of antigen-immunized rats received $10 \mathrm{mg} / \mathrm{kg}$ DHT intragastrically, $10 \mathrm{mg} / \mathrm{kg}$ Fe-Dex intraperitoneally and $20 \mathrm{mg} / \mathrm{kg}$ PMX administration, or a combination of these three toxins (DHT10 mg $/ \mathrm{kg}+10 \mathrm{mg} / \mathrm{kg} \mathrm{Fe}-\mathrm{Dex}+20 \mathrm{mg} / \mathrm{kg}$ PMX) to mimic calciphylaxis, respectively. At $\mathrm{d}_{84}$, the severity of DM manifestations in each rat was scored according to the assessment method described in Lennon et al (18). At $\mathrm{d}_{91}$, rats were euthanized by exsanguination under anesthesia with intraperitoneal injection of sodium pentobarbital $(50 \mathrm{mg} / \mathrm{kg})$, and were immobilized in the supine position with spontaneous breathing, the bloods were collected, and skin and skeletal muscles were collected from the limbs for further analysis (Fig. 1).

DM clinical score. DM manifestation in each animal was scored as described by assessment of muscle weakness as described by Lennon et al (18), to mimic that used climactically for patients. The scoring criteria are shown in Table I.

Pathological observation. The skin and skeletal muscle tissue samples were fixed in PBS-buffered $10 \%$ formalin. Following paraffin embedding, the tissue sections $(6 \mu \mathrm{m})$ were stained with hematoxylin and eosin (H\&E) or von Kossa using standard protocols. Briefly, the HE staining procedures were as follows: Slides were deparaffinized using xylene, hydrated using a gradient of alcohols solutions (100, 95 and $80 \%)$ 
Table I. Manifestation score in rats with dermatomyositis.

\begin{tabular}{|c|c|}
\hline Score & Symptom \\
\hline 0 & No definite weakness \\
\hline 1 & Weak grip or cry with fatigability, edema of limbs \\
\hline 2 & $\begin{array}{l}\text { Hunched posture with head down, movements unco- } \\
\text { ordinated, and forelimb digits flexed }\end{array}$ \\
\hline 3 & $\begin{array}{l}\text { Severe generalized weakness, tremulous, and mori- } \\
\text { bund }\end{array}$ \\
\hline
\end{tabular}

followed by distilled water. Secondly, the slides were stained with hematoxylin solution for $5 \mathrm{~min}$, rinsed with tap water, differentiated using $10 \%$ acetic acid in $95 \%$ alcohol for $1 \mathrm{~min}$ and rinsed with tap water. Finally, the slides were stained with eosin Y solution for 2 3 min, rinsed with $80 \%$ alcohol, dehydrated using a gradient of alcohols solutions $(95,100 \%)$, and then cleared with xylene. All these steps were performed at room temperature. Images were acquired using the Digital Pathology system (KFBIO), and pathological changes were quantified using Image Pro-Plus 7.0.1 (Media Cybernetics).

To quantify $\mathrm{T}$ lymphocyte infiltration, the lymphocyte infiltration areas (TA) and observed areas (OA) were measured under x20 magnification in skeletal muscle slides. The volume ratio of infiltrated $\mathrm{T}$ lymphocytes (ITL)was calculated using the formula: [(TA/OA $\left.)^{3 / 2} \times 100 \%\right]$ (14).

To quantify calcified nodules, the skeletal muscle tissue sections were stained at room temperature using the von Kossa method standard protocols. Briefly, after deparaffinizing and dehydrating, the slide was treated with $5 \%$ silver nitrate solution for $30 \mathrm{~min}$, exposed to incandescent light for $60 \mathrm{~min}$, and then treated with $5 \%$ sodium thiosulfate for $1 \mathrm{~min}$. Finally, the slides were washed and stained with eosin for $10 \mathrm{~min}$ to made the plasma exhibit thin red. Calcified nodules area (CA) in arteriole and arteriole areas (AA) were analyzed under $\mathrm{x} 40$ magnification. The volume ratio of calcified nodules in arteriole was calculated using the formula: [(CA/AA $\left.)^{3 / 2} \times 100 \%\right](15)$.

Antibody and cytokine measurement. At $\mathrm{d}_{14}$, one rat was randomly selected from the antigen-immunized rats, and the blood was obtained from its tail vein $(1 \mathrm{ml})$ (19). The blood sample was centrifuged at $3,000 \mathrm{xg}$ for $15 \mathrm{~min}$ at $4^{\circ} \mathrm{C}$, and the serum was collected and stored at $-80^{\circ} \mathrm{C}$ until analysis. The specific antibodies against plasma membrane antigen were detected using the agar immunodiffusion method. Briefly, an agar plate was prepared, and holes (diameter, $3 \mathrm{~mm}$ ) were drilled into the agar $\sim 5 \mathrm{~mm}$ apart. The prepared allogeneic plasma membrane antigen from the aforementioned donor animals or serum was added to the antigen well or sample well, respectively, and the plates were incubated at $37^{\circ} \mathrm{C}$ for $72 \mathrm{~h}$. A sample well was filled with normal saline as a negative control. Lastly, the plates were stained with Coomassie brilliant blue to display the immunocomplexes. Images were acquired using a digital camera (Canon, Inc.).

The serum levels of antibodies (anti-Jo-1 and anti-MDA5 antibodies) or cytokines (TNF- $\alpha$ and IFN- $\gamma$ ) from all rats were measured by ELISA using the double-antigen ('antibody sandwich') method according to the manufacturer's protocols (11).
A

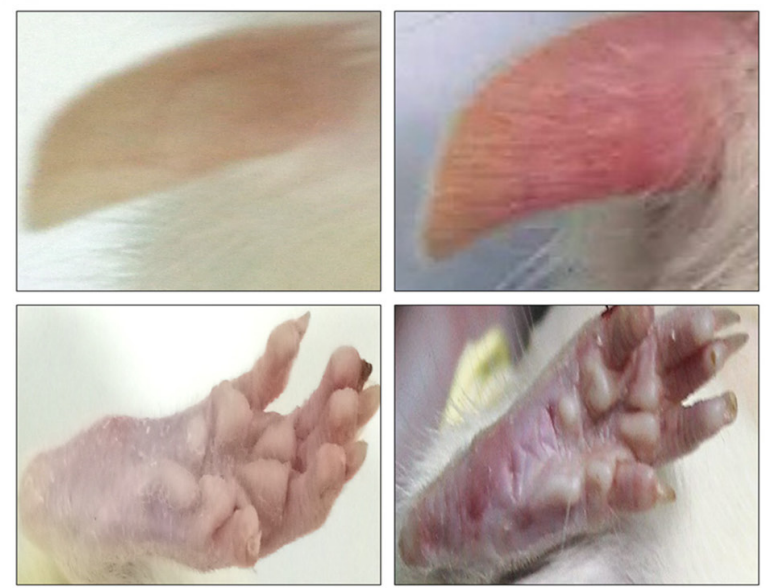

B

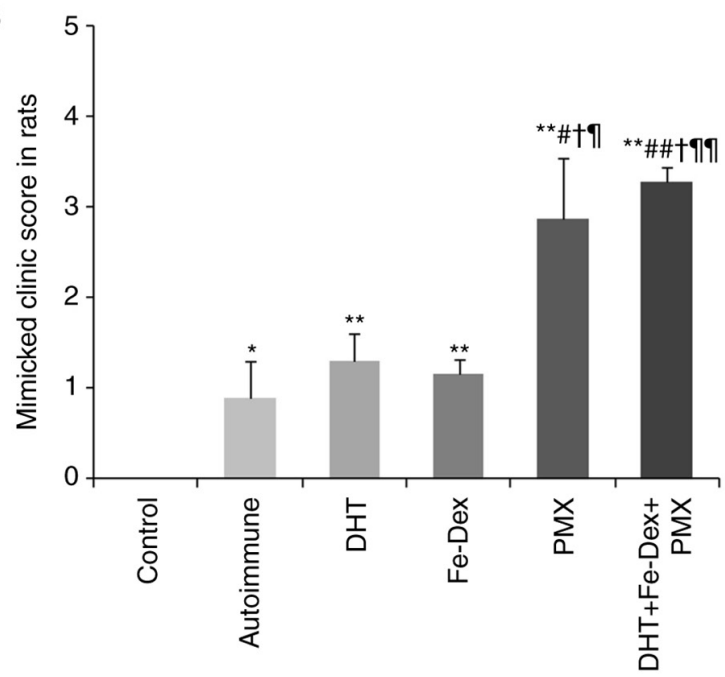

Figure 2. Manifestations and clinical score of DM model rats (A) Hyperemia and edema were observed in the ears and limbs of rats in the DHT + Fe-Dex + PMX group, but not in the control rats. (B) DM clinical score. The data are presented as the mean $\pm \mathrm{SD} . \mathrm{n}=8 .{ }^{*} \mathrm{P}<0.05,{ }^{* *} \mathrm{P}<0.01$ vs. control; ${ }^{\#} \mathrm{P}<0.05,{ }^{\# \#} \mathrm{P}<0.01$ vs. autoimmune; ${ }^{\dagger} \mathrm{P}<0.05$ vs. DHT group; ${ }^{9} \mathrm{P}<0.05,{ }^{\text {II }} \mathrm{P}<0.01$ vs. Fe-Dex group. DM, dermatomyositis; DHT, dihydrotestosterone; Fe-Dex, iron-dextrin; PMX, polymyxin.

The concentration of pre-coated rat Jo-1 or MDA5 antigen was 1.5 or $2.5 \mu \mathrm{g} / \mathrm{ml}$, respectively. The concentration of pre-coated anti-TNF- $\alpha$ or anti-IFN- $\gamma$ antibody was both $2.0 \mu \mathrm{g} / \mathrm{ml}$. The optical density at $450 \mathrm{~nm}$ was measured using a microplate reader (M1000; Tecan Group, Ltd.), and the concentrations were calculated by converting the optical density using a standard curve.

Statistical analysis. The data are presented as means \pm SD. The differences between groups were analyzed with SPSS 16.0 software (SPSS, Inc.) with non-parametrical test using a Kruskal-Wallis' test followed by a Dunn's post-hoc test. Correlation analysis between two data was performed using Spearman's correlation analysis. $\mathrm{P}<0.05$ was considered to indicate a statistically significant difference.

\section{Results}

Mimic clinical score in rats with DM. The clinical score in $\mathrm{DM}$ rats showed that 2 weeks after the antigen immunization 
Control

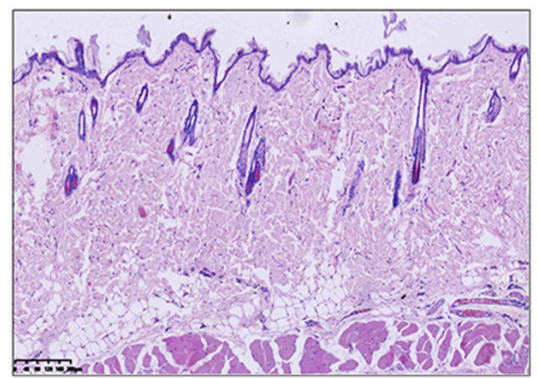

Fe-Dex

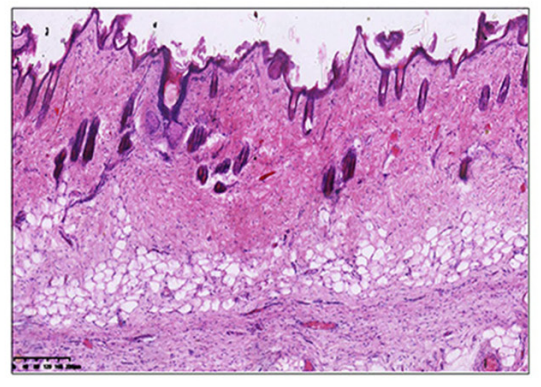

Autoimmune

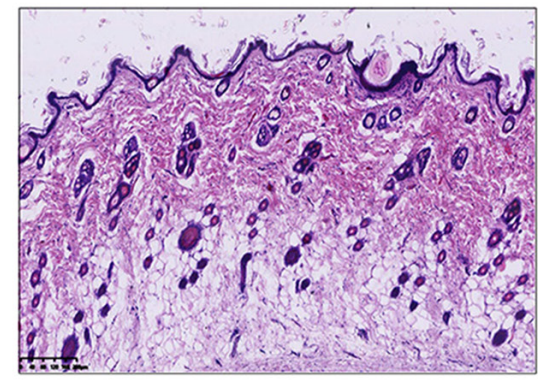

PMX

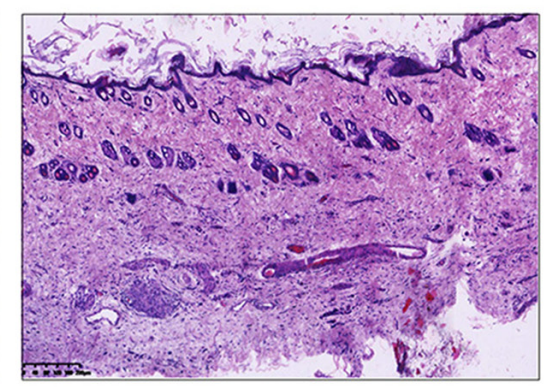

DHT

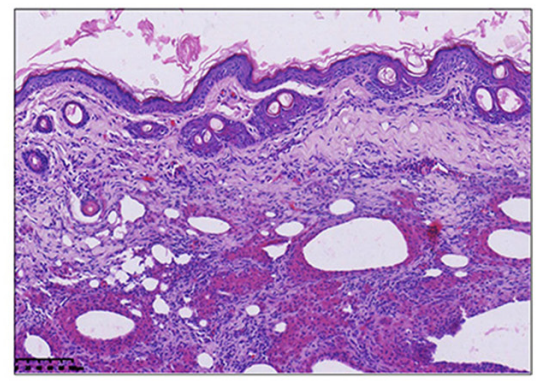

$\mathrm{DHT}+\mathrm{Fe}-\mathrm{Dex}+\mathrm{PMX}$

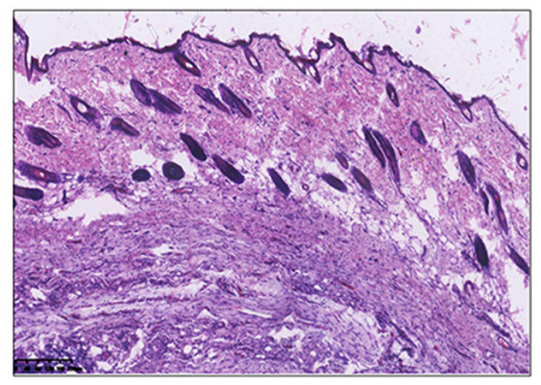

Figure 3. Pathological changes in the skin of DM model rats. Hematoxylin and eosin staining demonstrated that the DM model rats showed dyskeratotic keratinocytes, basement membrane thickening, lymphocytes and few neutrophils infiltrated in the dermis. Scale bar, $100 \mu \mathrm{m}$.

challenge, rats that received membrane antigen immunization without the toxins presented local cutaneous swelling and enlarged lymph nodes caused by the injected skin drainage. Following toxin administration to induce calciphylaxis (DHT, Fe-Dex, PMX or all three combined), rats exhibited marked weakness, ear hyperemia, and limb edema, especially in the PMX and DHT + Fe-Dex + PMX groups (Fig. 2A). The clinical scores in the PMT and DHT + Fe-Dex + PMX groups were higher than those in the antigen-immunized, DHT, and Fe-Dex groups (Fig. 2B). These results demonstrated that the lesions in rats that received with PTM and DHT + Fe-Dex + PMX were most similar to the clinical manifestations seen in patients.

Pathological changes of skins and skeletal muscles in rats with DM. To evaluate autoimmune injury, the pathological changes in the skin and skeletal muscles of DM model rats were observed using HE staining. In the skin tissue sections, rats in all five autoimmune groups showed dyskeratotic keratinocytes, basement membrane thickening, lymphocytes and few neutrophils infiltrated in the dermis. These changes were obvious in Fe-Dex and DHT + Fe-Dex + PMX groups (Fig. 3).

In the skeletal muscle tissue, compared with the control group, all the autoimmune groups showed edema and necrotic of muscle fibers, perifascicular atrophy, as well as perifascicular and perivascular lymphocytes infiltration (Fig. 4A). The morphometry results showed that the volume ratio of ITL was significantly increased in all the autoimmune groups. Moreover, the ITL volume ratio in the DHT + Fe-Dex + PMX group was higher than those in the antigen-immunized $(\mathrm{P}<0.05)$, DHT $(\mathrm{P}<0.01)$ and Fe-Dex $(\mathrm{P}<0.05)$ groups (Fig. 4B). This indicated that antigen immunization followed by DHT + Fe-Dex + PMX administration may represent the suitable model for DM.

Cutaneous calciphylaxis in rats with dermatomyositis. Calciphylaxis was analyzed following calcified nodule staining using the von Kossa method. The calcified nodules stained as black deposits, which were most apparent in the DHT + Fe-Dex + PMX group (Fig. 4C). The severity of cutaneous calciphylaxis was measured as the volume ratio of calcified nodules in arterioles. Compared with the control, the calciphylaxis ratio in the PMX $(\mathrm{P}<0.05)$ and $\mathrm{DHT}+\mathrm{Fe}-\mathrm{Dex}+\mathrm{PMX}$ groups was significantly increased $(\mathrm{P}<0.01)$. The rats in the DHT + Fe-Dex + PMX group had the highest ratio of calcified nodules in arterioles (Fig. 4D).

Changes in autoimmune antibody and cytokine levels in rats with DM. Autoimmune injury was demonstrated to have occurred based on the production of special antigens. Positivity for antibodies against plasma membrane antigens, as well as anti-Jo-1 antibody, anti-MDA5 antibody, TNF- $\alpha$ and IFN- $\gamma$ were used to evaluate autoimmune injury.

In the agar immunodiffusion assay, of one randomly selected rats from the antigen-immunized animals, positive precipitate line was observed, which indicated production of specific antigens against membrane antigens (Fig. 5A).

Anti-MDA5 and anti-Jo-1 antibodies are important biomarkers for DM diagnosis (20). The levels of anti-Jo-1 antibody in the PMX and DHT + Fe-Dex + PMX groups increased significantly compared with those in the control $(\mathrm{P}<0.01)$. Among the four calciphylaxis groups, anti-Jo-1 antibody levels in DHT + Fe-Dex + PMX group was greater than those in the antigen-immunized $(\mathrm{P}<0.05)$, DHT $(\mathrm{P}<0.05)$, and Fe-Dex $(\mathrm{P}<0.05)$ groups $($ Fig. $5 \mathrm{~B})$. The serum anti-MDA5 antibody levels in all five autoimmune groups were increased significantly compared with those of the control (Fig. 5C).

As markers for the severity and prognosis of DM (21), the levels of IFN- $\gamma$ and TNF- $\alpha$ were measured. IFN- $\gamma$ is the signature cytokine of $\mathrm{T}$ helper 1 cells, and its levels increased in patients with DM in parallel with the progression of muscle weakness (22). In the present study, IFN- $\gamma$ 
A

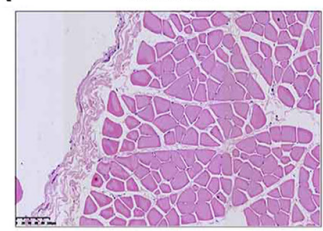

Fe-Dex

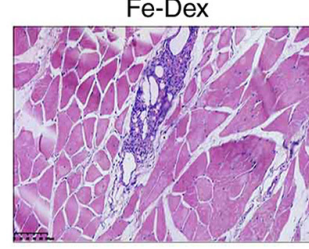

C

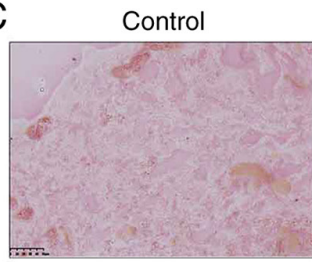

Fe-Dex

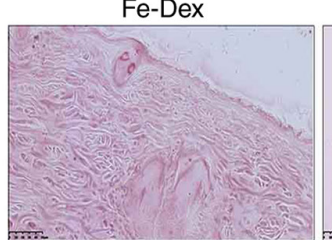

Autoimmune

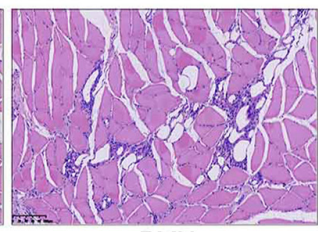

PMX

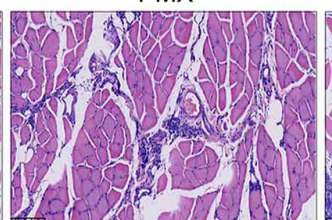

Autoimmune

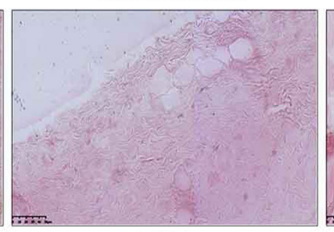

PMX

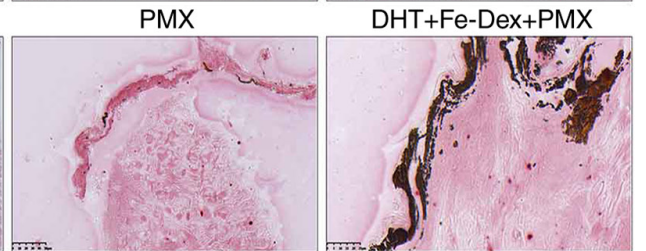

DHT

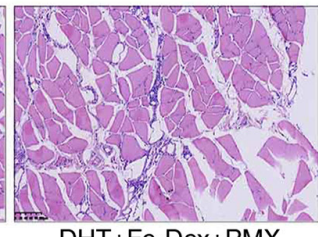

$\mathrm{DHT}+\mathrm{Fe}-\mathrm{Dex}+\mathrm{PMX}$

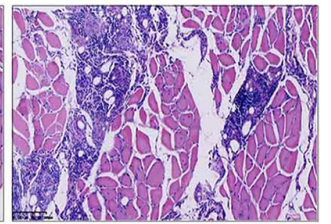

DHT

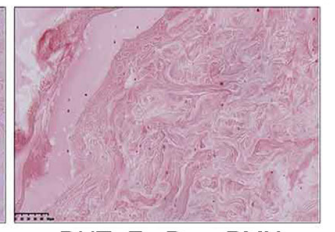

Do

Figure 4. Pathological observation and cutaneous calcified nodules. (A) T lymphocyte infiltration was detected using hematoxylin and eosin staining. There were no lesions in the control group. Edema or necrotic of muscle fibers and severe perifascicular atrophy were noted in the other five groups. T lymphocytes infiltrated the muscle fibers, perivascular areas, and perimysium. Scale bar, $50 \mu \mathrm{m}$. (B) The ratio of T lymphocyte infiltration in skeletal muscles. (C) Calcified nodules in cutaneous tissue were detected using von Kossa staining. There were rare arteriole calcified nodules in the PMX group. The DHT + Fe-Dex + PMX group presented numerous calcified nodules. The control and autoimmune groups did not have any calcified nodules. Scale bar: $25 \mu \mathrm{m}$. (D) The volume ratio of calcified nodules in arterioles. The data are presented as the mean $\pm \mathrm{SD} . \mathrm{n}=8 .{ }^{*} \mathrm{P}<0.05,{ }^{* *} \mathrm{P}<0.01$ vs. control; ${ }^{\#} \mathrm{P}<0.05,{ }^{\# \#} \mathrm{P}<0.01$ vs. autoimmune; ${ }^{\dagger} \mathrm{P}<0.05$, ${ }^{\dagger} \mathrm{P}<0.01$ vs. DHT group; ${ }^{9} \mathrm{P}<0.05$ vs. Fe-Dex group. DHT, dihydrotestosterone; Fe-Dex, iron-dextrin; PMX, polymyxin.

levels increased significantly in the PMX $(\mathrm{P}<0.05)$ and $\mathrm{DHT}+\mathrm{Fe}-\mathrm{Dex}+\mathrm{PMX}(\mathrm{P}<0.05)$ groups compared with the control group. Among all autoimmune groups, IFN- $\gamma$ levels in the DHT + Fe-Dex + PMX group were the highest (Fig. 5D). TNF- $\alpha$ directly regulates muscle metabolism and regeneration (23). The levels of TNF- $\alpha$ significantly increased in the PMX $(\mathrm{P}<0.05)$ and DHT + Fe-Dex + PMX $(\mathrm{P}<0.01)$ groups compared with the control group (Fig. 5E).

Calciphylaxis aggravates autoimmune injury in rats with DM. Correlation analysis was performed (Table II). The results indicated that the clinical scores correlated with indicators of autoimmune injury (IFN- $\gamma$, ITL, TNF- $\alpha$, anti-Jo-1 and anti-MDA5 antibody) and cutaneous calciphylaxis. Moreover, cutaneous calciphylaxis was also correlated with indicators of autoimmune injuries (IFN- $\gamma$, ITL, TNF- $\alpha$, and anti-Jo-1 antibody).

\section{Discussion}

DM is a serious systemic autoimmune disease characterized by skin rashes and progressive muscle weakness (3).
However, there are no specific treatments for DM (24). The lack of suitable animal model constrains novel drug discovery. Autoimmune injuries with slight cutaneous calciphylaxis are important factors involved in DM pathogenesis (3). In the present study, a rat model of DM was established using allogeneic plasma membrane antigen immunization and toxin-induced cutaneous calciphylaxis. The interventions used were optimized to replicate the lesions observed in patients with DM.

According to the pathophysiology of human DM, four aspects were designed as the evaluating system of a novel DM model for developing targeted therapies, i.e., muscle weakness, pathological features of heterogenic autoimmune injury, slight cutaneous calciphylaxis, and the molecules that are involved in autoimmune injuries.

According to the diagnostic criteria, the DM model developed in the present study mimicked the main clinical manifestations of the disease, such as muscle weakness and characteristic cutaneous hyperemia. Muscle weakness gradually aggravated during this experimental process. The cutaneous hyperemia or edema in ear or limb skins appeared consequently. Rats receiving PMX alone or DHT, Fe-Dex 


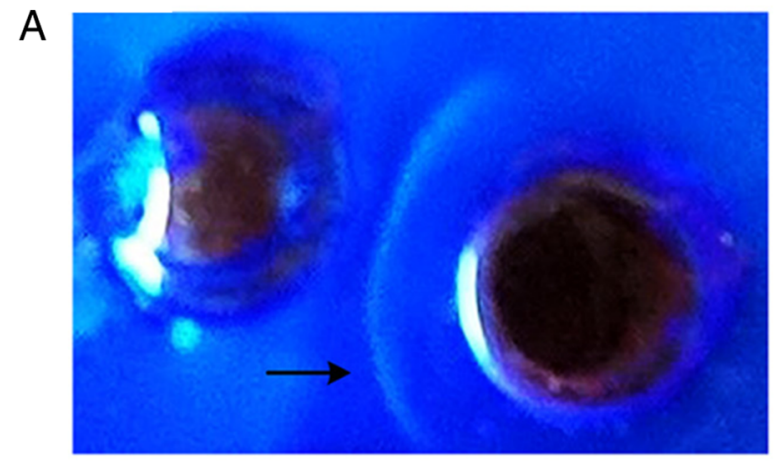

B

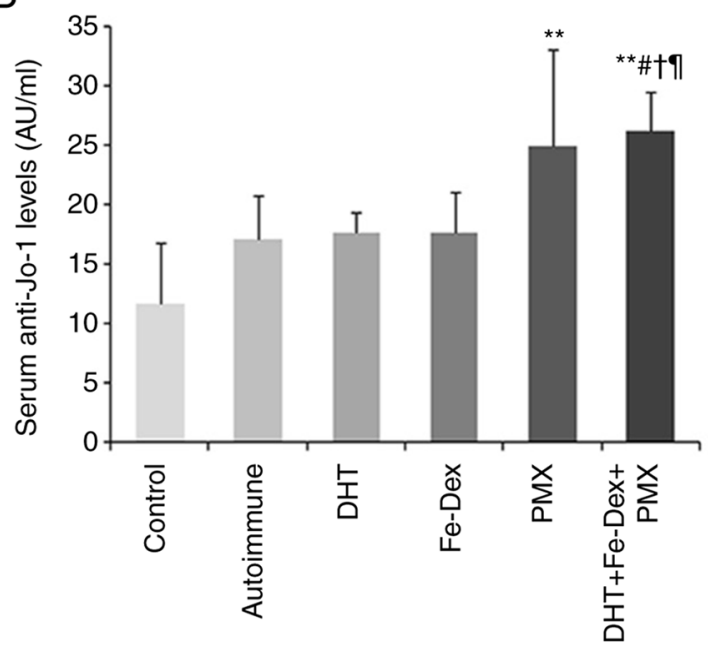

D

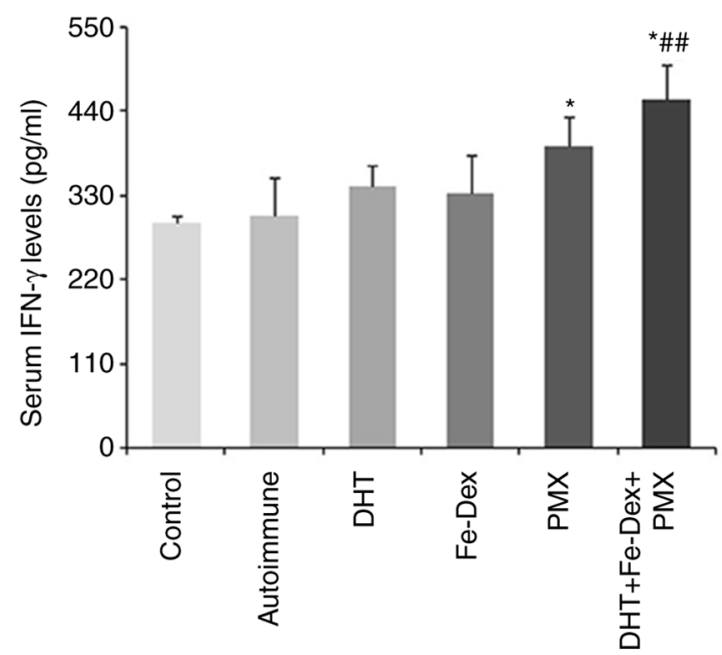

C

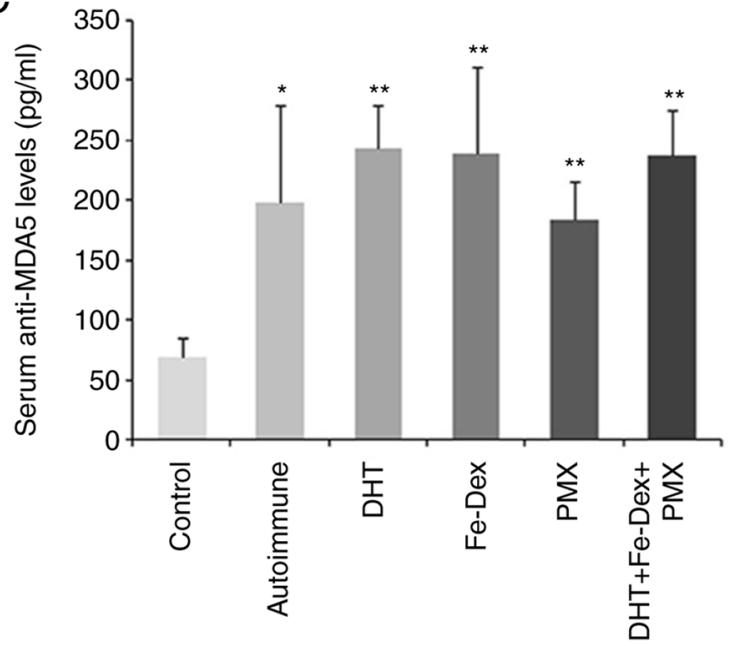

$E$

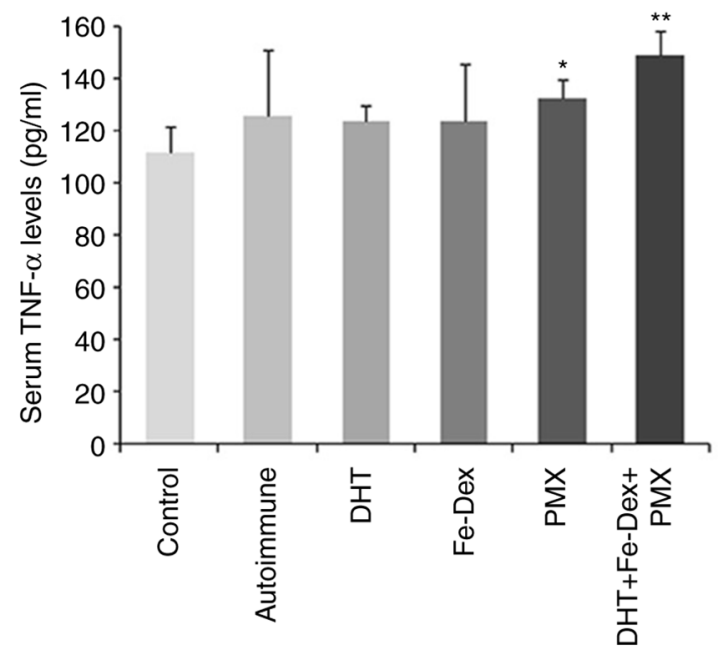

Figure 5. Detection of antibodies and cytokines in rats. (A) Agar gel immunodiffusion assay used for detecting serum antibodies against membrane antigens from one randomly selected rat from the antigen immunized group. The production of antigen-antibody immunocomplexes was confirmed based on the presence of white crescent precipitate lines (B) Levels of anti-Jo-1 antibodies in serum. (C) Levels of anti-MDA5 antibodies in serum. (D) Levels of IFN- $\gamma$ in serum. (E) Levels of TNF- $\alpha$ in serum. The data are presented as the mean $\pm \mathrm{SD} . \mathrm{n}=8 .{ }^{*} \mathrm{P}<0.05,{ }^{* *} \mathrm{P}<0.01 \mathrm{vs}$. control; ${ }^{\#} \mathrm{P}<0.05,{ }^{\# \#} \mathrm{P}<0.01 \mathrm{vs}$. autoimmune; ${ }^{\dagger} \mathrm{P}<0.05$ vs. DHT group; 'P<0.05 vs. Fe-Dex group. DHT, dihydrotestosterone; Fe-Dex, iron-dextrin; PMX, polymyxin; IFN- $\gamma$, interferon- $\gamma$; TNF- $\alpha$, tumor necrosis factor- $\alpha$; Jo-1, histidyl tRNA synthetase; MDA5, melanoma differentiation-associated protein 5.

and PMX combined showed obvious clinical manifestations, which started at $30 \mathrm{~min}$ after administration of the toxins and lasted until the endpoint of the experimental procedure.

The general pathological features of DM include inflammation of muscles, skin, and blood vessels (25). The gross feature of human DM has been described as red or purple rashes in affected skin, fixed locations (chest, face, neck, upper back, shoulders, ankles, and knees) appearing as a sunburn, being possible rough, dry, and scaly, leading to calcium deposits under the skin, forming nodules (26). These inflammatory damages occurring in muscle tissue result in pain, weakness, and atrophy (27). The microscopic characteristics of 
Table II. Correlation analysis between score and autoimmune injury, or calciphylaxis and autoimmune injury.

\begin{tabular}{lcr}
\hline Parameters & Spearman's coefficient & P-values \\
\hline Score & & \\
IFN- $\gamma$ & 0.823 & $<0.001^{\mathrm{b}}$ \\
ITL & 0.730 & $<0.001^{\mathrm{b}}$ \\
TNF- $\alpha$ & 0.595 & $<0.001^{\mathrm{b}}$ \\
Anti-Jo-1 & 0.663 & $<0.001^{\mathrm{b}}$ \\
Anti-MDA5 & 0.442 & $0.008^{\mathrm{a}}$ \\
ACN & 0.760 & $<0.001^{\mathrm{b}}$ \\
ACN & & \\
IFN- $\gamma$ & 0.673 & $<0.001^{\mathrm{b}}$ \\
TNF- $\alpha$ & 0.433 & $0.009^{\mathrm{a}}$ \\
ITL & 0.495 & $0.002^{\mathrm{a}}$ \\
Anti-Jo-1 & 0.480 & $0.004^{\mathrm{a}}$ \\
\hline
\end{tabular}

${ }^{\mathrm{a}} \mathrm{P}<0.01,{ }^{\mathrm{b}} \mathrm{P}<0.001$. ITL, infiltrated lymphocyte; $\mathrm{ACN}$, arteriole calcified nodule; IFN- $\gamma$, interferon- $\gamma$; TNF- $\alpha$, tumor necrosis factor- $\alpha$; Jo-1, histidyl tRNA synthetase; MDA5, melanoma differentiation-associated protein 5 .

human DM have been described as an autoimmune-mediated inflammation in skeletal muscle and its nearby subcutaneous connective tissue, which was observed as necrosis and phagocytosis, regeneration, perifascicular atrophy, internal nuclei, fiber vacuolation, fiber diameter variation, mononuclear cell infiltration (lymphocyte, macrophage and plasma cell) in perimysial and endomysial connective tissue $(11,28)$. In the present study, focusing on the autoimmune injuries in the DM rats, perifascicular fiber atrophy, necrosis of muscle fiber, degenerative changes in intramuscular capillaries, and $\mathrm{T}$ lymphocyte infiltration were examined. The analysis showed that increased ratios of infiltrated $\mathrm{T}$ lymphocytes were detectable in this model.

Cutaneous calciphylaxis is a systemic process characterized with arterial calcification, microthrombosis, and fibrointimal hyperplasia in arterioles, even leading to ischemia and necrosis (29). The rats that were administered all three toxins combined exhibited numerous arteriole calcified nodules, those in the PMX exhibited few calcified nodules, and those in the DHT or Fe-Dex groups only had scattered calcified nodules. The inflammatory cells may release hydrogen ions leading to an acidic environment, then resulting in phosphate dissociation (30). When high levels of calcium-phosphate products form, calcific deposition occurs in arterioles, which is described as calcified nodules $(31,32)$ are considered predisposing factors in DM pathogenesis (9). Autoimmune injury sensitizes the animals to toxin-induced calciphylaxis (33). In the present study, calcified nodules in arterioles in cutaneous tissue positively correlated with indicators of autoimmune injury, such as IFN- $\gamma$ level, TNF- $\alpha$ level, T lymphocyte infiltration, and anti-Jo-1 antibody levels. Slight calciphylaxis also aggravates the clinical manifestations and autoimmune injuries (lymphocyte infiltration and cytokines). The morphometry analysis showed an increased ratio of

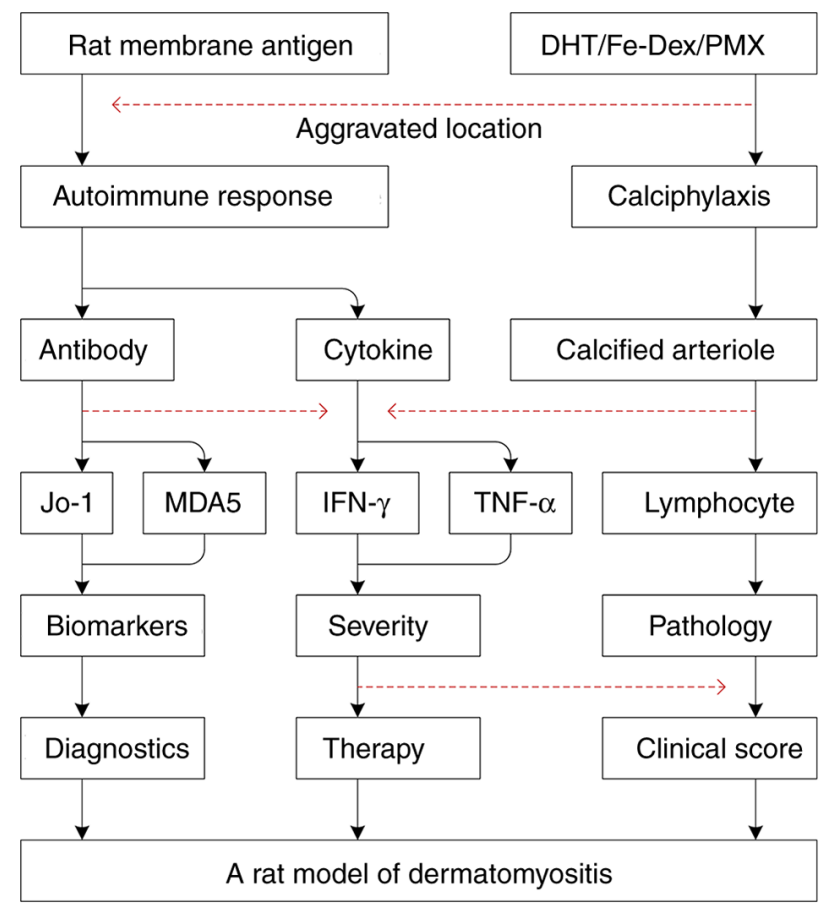

Figure 6 . The dermatomyositis animal model induced by membrane antigen The dermatomyositis animal model was induced by rat plasma membrane antigen combining DHT, Fe-Dex and PMX, the autoimmune response was induced by the former and the cutaneous calciphylaxis was induced by the latter. Autoimmune responses leads to antibody and cytokine secretion. Anti-Jo-1 and anti-MDA5 antibodies are biomarkers used in DM diagnosis, the increased serum levels of IFN- $\gamma$ and TNF- $\alpha$ are observed following the activation of type-IV hypersensitivity. Calciphylaxis aggravates the autoimmune response in skin and muscle, leading to cutaneous calcified nodules in arterioles and $\mathrm{T}$ lymphocyte infiltration in skeletal muscle. The lesions observed in this rat model of dermatomyositis are similar to those observed in patients. IFN- $\gamma$, interferon- $\gamma$; TNF- $\alpha$, tumor necrosis factor- $\alpha$; Jo- 1 , histidyl tRNA synthetase; MDA5, melanoma differentiation-associated protein 5.

calcified nodules in arterioles, which demonstrated a slight degree of cutaneous calciphylaxis in this model.

In the present study, autoimmune injury was induced with plasma membrane antigen that extracted from the skeletal muscle and its nearby cutaneous tissues. Autoimmune injury consists of tissue damage resulting from immunological mechanisms; the four types of hypersensitivity always play roles in the pathogenesis of autoimmune disorders: i) Type I-immunoglobulin (Ig) E and mast cells; ii) type II-IgM, IgG and complement; iii) type III-IgG immunocomplexes; and type IV T lymphocytes and macrophages (34-36). In the present study, 14 days after membrane antigen stimulation, positive precipitation lines were observed in agar immunodiffusion assays carried out in randomly selected rats. However, this assay was not performed in all autoimmune rats, which is the limitation of this study.

Furthermore, the presence of antibodies specific for autologous plasma membrane antigens were found in the sera of autoimmune rats, suggesting possible antibody-dependent damage. In addition, type-II or -III hypersensitivity may be involved in the injury mechanism in the antigen-sensitized rats. Finally, it was demonstrated that type II hypersensitivity-associated mechanisms taking part in the antibody-dependent damage in this DM model, which was confirmed based on the increased levels of serum unique 
antibodies (Jo-1/MDA5) and the cellular swelling of muscle fibers (2,37-39). Antibody-independent damage, associated with type-IV hypersensitivity, was confirmed in this DM model, which was evidenced by the pathological characteristics of the skeletal muscle and the increased levels of serum cytokines (TNF- $\alpha / \mathrm{IFN}-\gamma)(22,40-42)$. Each biomarker in this process positively correlated with the clinical score or the pathological changes. The pathogenesis of DM, initiated by cellular immune injuries, and the increased levels of specific antibodies in the sera were the results of autoimmune lesions, which were consistent with the diagnosis of DM patients in clinics (Fig. 6).

In conclusion, a novel DM model in rats was developed from both of the autoimmune injuries induced with autologous plasma membrane antigen and toxin-induced cutaneous calciphylaxis. The autoimmune injury mimicked the leading mechanisms in DM pathogenesis, and the slight cutaneous calciphylaxis was a precipitating factor that aggravated the observed lesions. In this model, there is a wide observational window that could satisfy experimental studies, with a fixed interval between antigen immunization and cutaneous calciphylaxis (from 6 to 13 weeks). This model may prove useful for the evaluation of the mechanisms of DM pathogenesis and may facilitate the development of novel DM treatment methods.

\section{Acknowledgements}

Not applicable.

\section{Funding}

This work was supported by The National Natural Science Foundation of China (grant nos. 81541082 and 81673674 and The Chinese Academy of Medical Sciences Medical and Health Science and Technology Innovation Project (grant no. 2018-I2M-AI-015).

\section{Availability of data and materials}

The datasets used and/or analyzed during the current study are available from the corresponding author on reasonable request.

\section{Authors' contributions}

DC designed the study. DC, XZ and LL drafted and revised the manuscript. XZ and LL performed the experiments and analyzed the data. SG, JL, SL and HW performed the experiments. All authors have read and approved the final manuscript. DC, XZ and LL confirm the authenticity of all the raw data.

\section{Ethics approval and consent to participate}

This retrospective study was approved by The Ethics Committee of the Institute of Medicinal Plant Development, Chinese Academy of Medical Sciences \& Peking Union Medical College (approval no. SLXD-20170705016).

\section{Patient consent for publication}

Not applicable.

\section{Competing interests}

The authors declare that they have no competing interests.

\section{References}

1. Santo AH, Souza JM, Pinheiro CE, Souza DC and Sato EI: Trends in dermatomyositis- and polymyositis-related mortality in the state of Sao Paulo, Brazil, 1985-2007: Multiple cause-of-death analysis. BMC Public Health 10: 597, 2010.

2. Johnson C, Connors GR, Oaks J, Han S, Truong A, Richardson B, Lechtzin N, Mammen AL, Casciola-Rosen L, Christopher-Stine L and Danoff SK: Clinical and pathologic differences in interstitial lung disease based on antisynthetase antibody type. Respir Med 108: 1542-1548, 2014.

3. DeWane ME, Waldman R and Lu J: Dermatomyositis: Clinical features and pathogenesis. J Am Acad Dermatol 82: 267-281, 2020.

4. Smith ES, Hallman JR, DeLuca AM, Goldenberg G, Jorizzo JL and Sangueza OP: Dermatomyositis: A clinicopathological study of 40 patients. Am J Dermatopathol 31: 61-67, 2009.

5. Vermaak E, Shaddick G and McHugh NJ: Mortality In Polymyositis and Dermatomyositis: A Single Centre Study. Arthritis Rheum-Us 65: S878-S878, 2013. https://www.webofscience.com/wos/alldb/full-record/WOS:000325359205007

6. Yang WM and Chen JJ: Advances in biomarkers for dermatomyositis. Clin Chim Acta 482: 172-177, 2018.

7. Sun KY, Fan Y, Wang YX, Zhong YJ and Wang GF: Prevalence of interstitial lung disease in polymyositis and dermatomyositis: A meta-analysis from 2000 to 2020. Semin Arthritis Rheum 51: 175-191, 2021.

8. Kao L, Chung L and Fiorentino DF: Pathogenesis of dermatomyositis: Role of cytokines and interferon. Curr Rheumatol Rep 13: 225-232, 2011.

9. Selye H, Gentile G and Jean P: An experimental model of 'dermatomyositis' induced by calciphylaxis. Can Med Assoc J 85: 770-776, 1961.

10. Aljabban J, Syed S, Rohr M, Weisleder N, McElhanon KE, Hasan L, Safeer L, Hoffman K, Aljabban N, Mukhtar M, et al: Investigating genetic drivers of dermatomyositis pathogenesis using meta-analysis. Heliyon 6: e04866, 2020.

11. Luo YB and Mastaglia FL: Dermatomyositis, polymyositis and immune-mediated necrotising myopathies. Biochim Biophys Acta 1852: 622-632, 2015.

12. Okiyama N, Ichimura Y, Shobo M, Tanaka R, Kubota N, Saito A, Ishitsuka Y, Watanabe R, Fujisawa Y, Nakamura Y, et al: Immune response to dermatomyositis-specific autoantigen, transcriptional intermediary factor $1 \gamma$ can result in experimental myositis. Ann Rheum Dis 80: 1201-1208, 2021.

13. Iaccarino L, Ghirardello A, Bettio S, Zen M, Gatto M, Punzi L and Doria A: The clinical features, diagnosis and classification of dermatomyositis. J Autoimmun 48-49: 122-127, 2014.

14. Shimojima Y, Matsuda M, Ishii W, et al:: Phenotypic analysis of lymphocytes using flow cytometry in dermatomyositis with and without interstitial pneumonia. In: Proceeding of the 8th International Congress of Neuroimmunology: 209-212, 2006. https://www.webofscience.com/wos/alldb/full-record/ WOS:000251732700043

15. Cassius C, Moguelet P, Monfort JB, Fessi H, Michel PA, Boulahia G, Cury K, Frances C and Senet P: Calciphylaxis in haemodialysed patients: Diagnostic value of calcifications in cutaneous biopsy. Br J Dermatol 178: 292-293, 2018.

16. Nemoto H, Bhopale MK, Constantinescu CS, Schotland D and Rostami A: Skeletal muscle myosin is the autoantigen for experimental autoimmune myositis. Exp Mol Pathol 74: 238-243, 2003.

17. Kang J, Zhang HY, Feng GD, Feng DY and Jia HG: Development of an improved animal model of experimental autoimmune myositis. Int J Clin Exp Pathol 8: 14457-14464, 2015.

18. Lennon VA, Lindstrom JM and Seybold ME: Experimental autoimmune myasthenia: A model of myasthenia gravis in rats and guinea pigs. J Exp Med 141: 1365-1375, 1975.

19. Abbas AK and Lichtman AH: Basic immunology: Functions and disorders of the immune system. Saunders, Philadelphia, PA, 2004.

20. Bodoki L, Nagy-Vincze M, Griger Z, Betteridge Z, Szollosi L and Danko K: Four dermatomyositis-specific autoantibodiesanti-TIF1Y, anti-NXP2, anti-SAE and anti-MDA5-in adult and juvenile patients with idiopathic inflammatory myopathies in a Hungarian cohort. Autoimmun Rev 13: 1211-1219, 2014. 
21. Ishikawa Y,Iwata S, Hanami K, Nawata A,ZZhang M, Yamagata K, Hirata S, Sakata K, Todoroki Y, Nakano K, et al: Relevance of interferon-gamma in pathogenesis of life-threatening rapidly progressive interstitial lung disease in patients with dermatomyositis. Arthritis Res Ther 20: 240, 2018.

22. Giris M, Durmus H, Yetimler B, Tasli H, Parman Y and Tuzun E: Elevated IL-4 and IFN-Y levels in muscle tissue of patients with dermatomyositis. In Vivo 31: 657-660, 2017.

23. Shinjo SK, de Souza FH and de Moraes JC: Dermatomyositis and polymyositis: From immunopathology to immunotherapy (immunobiologics). Rev Bras Reumatol 53: 101-110, 2013 (In English, Portuguese).

24. Sasaki H and Kohsaka H: Current diagnosis and treatment of polymyositis and dermatomyositis. Mod Rheumatol 28: 913-921, 2018.

25. Yang SH, Chang $\mathrm{C}$ and Lian ZX: Polymyositis and dermatomyositis-challenges in diagnosis and management. J Transl Autoimmun 2: 100018, 2019.

26. Dalakas MC and Hohlfeld R: Polymyositis and dermatomyositis. Lancet 362: 971-982, 2003.

27. Miller FW, Rider LG, Plotz PH, Isenberg DA and Oddis CV: Diagnostic criteria for polymyositis and dermatomyositis. Lancet 362: 1762-1763, 2003.

28. Goebels N, Michaelis D, Engelhardt M, Huber S, Bender A, Pongratz D, Johnson MA, Wekerle H, Tschopp J, Jenne D and Hohlfeld R: Differential expression of perforin in muscleinfiltrating $\mathrm{T}$ cells in polymyositis and dermatomyositis. J Clin Invest 97: 2905-2910, 1996.

29. Nigwekar SU, Kroshinsky D, Nazarian RM, Goverman J, Malhotra R, Jackson VA, Kamdar MM, Steele DJ and Thadhani RI: Calciphylaxis: Risk factors, diagnosis, and treatment. Am J Kidney Dis 66: 133-146, 2015.

30. Zhou Q, Neubauer J, Kern JS, Grotz W, Walz G and Huber TB: Calciphylaxis. Lancet 383: 1067, 2014.

31. Aghagolzadeh P, Bachtler M, Bijarnia R, Jackson C, Smith ER, Odermatt A, Radpour R and Pasch A: Calcification of vascular smooth muscle cells is induced by secondary calciprotein particles and enhanced by tumor necrosis factor- $\alpha$. Atherosclerosis 251 : 404-414, 2016.

32. Mathur RV, Shortland JR and el-Nahas AM: Calciphylaxis. Postgrad Med J 77: 557-561, 2001.
33. Romero-Díaz J, Vargas-Vóracková F, Kimura-Hayama E, Cortázar-Benítez LF, Gijón-Mitre R, Criales S, Cabiedes-Contreras J, Iñiguez-Rodríguez Mdel R, Lara-García EA, Núñez-Alvarez C, et al: Systemic lupus erythematosus risk factors for coronary artery calcifications. Rheumatology (Oxford) 51: 110-119, 2012.

34. Iammatteo M, Keskin T and Jerschow E: Evaluation of periprocedural hypersensitivity reactions. Ann Allergy Asthma Immunol 119: 349-355.e2, 2017.

35. Castells M: Diagnosis and management of anaphylaxis in precision medicine. J Allergy Clin Immunol 140: 321-333, 2017.

36. Javed B, Padfield P, Sperrin M, Simpson A and Mills ENC: A protocol for a systematic review to identify allergenic tree nuts and the molecules responsible for their allergenic properties. Food Chem Toxicol 106: 411-416, 2017.

37. Dourmishev LA, Dourmishev AL and Schwartz RA: Dermatomyositis: An association of gingival telangiectases and anti Jo-1 antibody in the adult. Acta Dermatovenerol Alp Pannonica Adriat 16: 67-72, 2007.

38. Sontheimer RD: MDA5 autoantibody-another indicator of clinical diversity in dermatomyositis. Ann Transl Med 5: 160, 2017.

39. Hoshino K, Muro Y, Sugiura K, Tomita Y, Nakashima R and Mimori T: Anti-MDA5 and anti-TIF1-gamma antibodies have clinical significance for patients with dermatomyositis. Rheumatology (Oxford) 49: 1726-1733, 2010.

40. Arshanapalli A, Shah M, Veerula V and Somani AK: The role of type I interferons and other cytokines in dermatomyositis. Cytokine 73: 319-325, 2015.

41. Brunasso AM, Aberer W and Massone C: New onset of dermatomyositis/polymyositis during anti-TNF- $\alpha$ therapies: A systematic literature review. ScientificWorldJournal 2014: 179180, 2014

42. Mamyrova G, O'Hanlon TP, Sillers L, Malley K, James-Newton L, Parks CG, Cooper GS, Pandey JP, Miller FW and Rider LG; Childhood Myositis Heterogeneity Collaborative Study Group: Cytokine gene polymorphisms as risk and severity factors for juvenile dermatomyositis. Arthritis Rheum 58: 3941-3950, 2008.

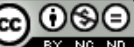

This work is licensed under a Creative Commons Attribution-NonCommercial-NoDerivatives 4.0 International (CC BY-NC-ND 4.0) License. 